\title{
Intratesticular Simple Cyst - Ultrasound and Elastography Appearance
}

\author{
Pratik Jayaprakash Bhansali¹, Suresh Vasant Phatak², Lakshmi Bishnoi ${ }^{3}$, Nishant Raj ${ }^{4}$ \\ 1, 2, 3, 4 Department of Radio Diagnosis, Jawaharlal Nehru Medical College, \\ Sawangi (Meghe), Wardha, Maharashtra, India.
}

\section{ABSTRACT}

Simple intratesticular cysts are unusual lesions. They are mostly non-palpable and diagnosed incidentally. A fifty year old patient was presented for scrotal sonography due to vague scrotal pain. On examination, a $6.8 \times 5.4 \mathrm{~mm}$ intratesticular hypoechoic lesion was seen with imperceptible walls and posterior acoustic enhancement which is an indication of cystic lesion. This cyst contained echogenic mobile material indicating benign nature of the lesion (Figure 1). Strain elastography revealed typical blue green red (BGR) sign confirming cystic nature of lesion. (Figure 2)

Benign intra testicular lesions are uncommon, but proper diagnosis is important so that unnecessary surgical intervention is prevented. Benign lesions involve tubular ectasia, abscess, intra testicular varicocele, intratesticular simple cysts, epidermoid cyst, tunica albuginea cyst and hemorrhage. ${ }^{1}$ Gray-scale ultrasonography (USG) along with Color-Doppler ultrasound wherever possible mostly gives accurate diagnosis leading to appropriate treatment. ${ }^{2}$ Features of simple cyst on USG include an imperceptible wall, an anechoic center and through transmission. Simple cysts are incidental finding most commonly in males of age 40 years and above. Variable in size having diameter of two mili meters to two centimeters.

These are commonly single, in some cases multiple cysts have also been found. Simple cysts are commonly found near the mediastinum of testis but can also be found in other parts of testis. Also, these are linked with extra testicular spermatoceles.

On local examination, even large simple testicular cysts are generally not palpable as they are not firm. Tunica albuginea cysts are very firm. So, we can easily differentiate between tunica albuginea cyst and simple testicular cyst. ${ }^{3}$ Sometimes testicular cysts contain echoic material which is mobile with change in position (Figure 2). The mobility of material suggests whether the cyst is benign or if fixed, it can be a cyst of neoplastic etiology. ${ }^{4}$ The 3 - layer pattern (blue / green / red layers) visible in smaller cystic areas is known as the BGR sign and is visible in a few elastography systems.

This pattern is taken into consideration as beneficial because it highlights the cystic nature of the lesion and has been proven to be true even in cases of cystic lesions with inner echogenic material. ${ }^{5}$
Corresponding Author: Dr. Suresh Vasant Phatak, Dept of Radiodiagnosis, Jawaharlal Nehru Medical College, Sawangi (Meghe), Wardha - 442001,

Maharashtra, India.

E-mail:suresh_phatak@yahoo.com

DOI: $10.14260 / \mathrm{jemds} / 2021 / 326$

How to Cite This Article:

Bhansali PJ, Phatak SV, Bishnoi L, et al. Intratesticular simple cyst - ultrasound and elastography appearance J Evolution Med Dent Sci 2021;10(20):1561-1562, DOI: 10.14260/jemds/2021/326

Submission 07-01-2021,

Peer Review 15-03-2021,

Acceptance 23-03-2021,

Published 17-05-2021.

Copyright (c) 2021 Pratik Jayaprakash Bhansali et al. This is an open access article distributed under Creative Commons Attribution License [Attribution 4.0 International (CC BY 4.0)] 

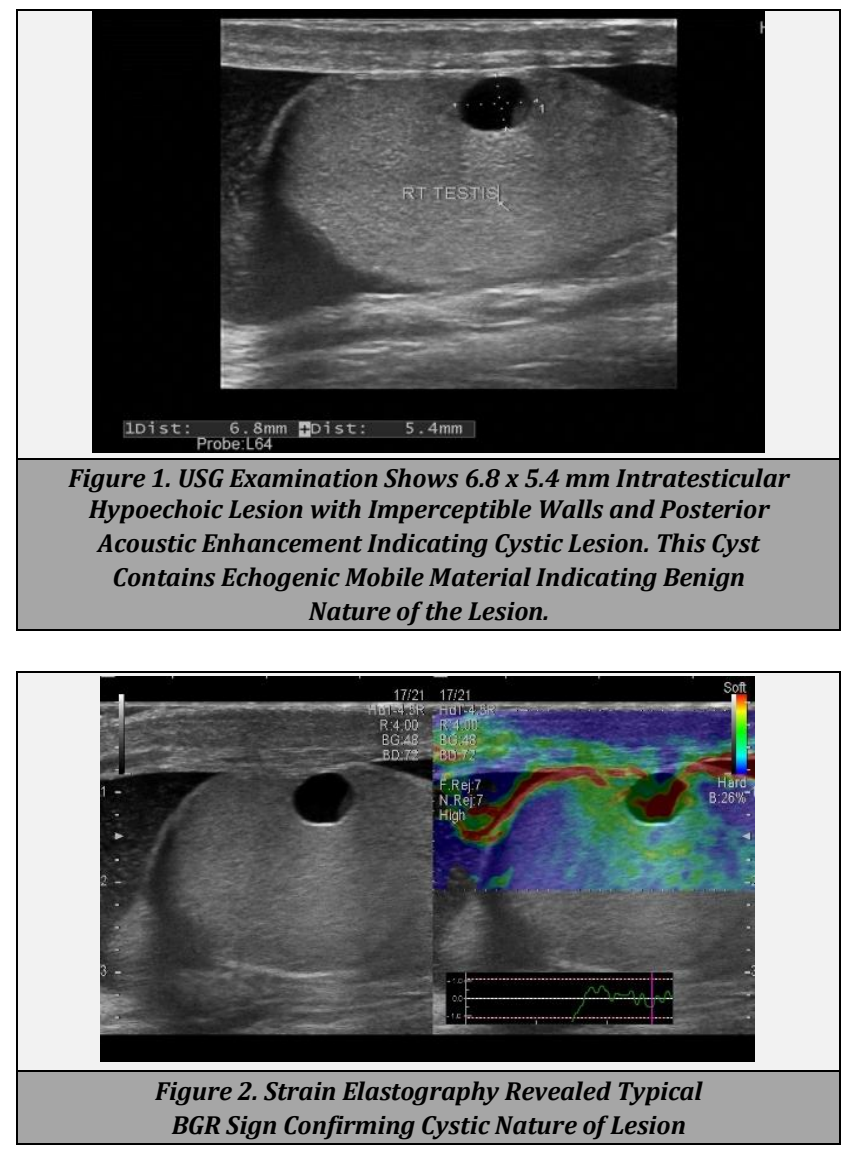

Financial or other competing interests: None.

Disclosure forms provided by the authors are available with the full text of this article at jemds.com.

\section{REFERENCES}

[1] Dogra VS, Gottlieb RH, Rubens DJ, et al. Benign intratesticular cystic lesions: US features. Radiographics 2001;21(Spec No.):S273-81.

[2] Valentino M, Bertolotto M, Ruggirello M, et al. Cystic lesions and scrotal fluid collections in adults: ultrasound findings. J Ultrasound 2011;14(4):208-15.

[3] Gooding GA, Leonhardt W, Stein R. Testicular cysts: US findings. Radiology 1987;163(2):537-8.

[4] Algaba F, Mikuz G, Boccon-Gibod L, et al. Pseudoneoplastic lesions of the testis and paratesticular structures. Virchows Arch 2007;451(6):987-97.

[5] Cho N, Moon WK, Chang JM, et al. Aliasing artifact depicted on ultrasound (US)- elastography for breast cystic lesions mimicking solid masses. Acta Radiol 2011;52(1):3-7. 